Article

\title{
Fragility Analysis of RC Frame Structures Subjected to Obliquely Incident Seismic Waves
}

\author{
Bo Huang ${ }^{1,2} \mathbb{D}$, Jiachen Guo ${ }^{1,2}$, Kailong Liao ${ }^{1,2}$ and Yu Zhao ${ }^{1,2, *}$ \\ 1 Institute of Geotechnical Engineering, Zhejiang University, Hangzhou 310058, China; \\ cehuangbo@zju.edu.cn (B.H.); jiachenguo@zju.edu.cn (J.G.); 1152358617@zju.edu.cn (K.L.) \\ 2 MOE Key Laboratory of Soft Soils and Geoenvironmental Engineering, Zhejiang University, \\ Hangzhou 310058, China \\ * Correspondence: zhao_yu@zju.edu.cn; Tel.: +86-571-88208732
}

Citation: Huang, B.; Guo, J.; Liao, K.; Zhao, Y. Fragility Analysis of RC

Frame Structures Subjected to Obliquely Incident Seismic Waves. Sustainability 2021, 13, 1108. https://doi.org/10.3390/ su13031108

Received: 23 December 2020 Accepted: 18 January 2021 Published: 21 January 2021

Publisher's Note: MDPI stays neutral with regard to jurisdictional clai$\mathrm{ms}$ in published maps and institutional affiliations.

Copyright: (C) 2021 by the authors. Licensee MDPI, Basel, Switzerland. This article is an open access article distributed under the terms and conditions of the Creative Commons Attribution (CC BY) license (https:// creativecommons.org/licenses/by/ $4.0 /)$.

\begin{abstract}
Obliquely incident seismic waves have been habitually overlooked in fragility analysis. In this paper, a new approach to solving the equivalent loads on the infinite element boundary due to obliquely incident seismic waves is proposed. Based on the site conditions and structural characteristics in the Jiaxing area, the seismic response of a multi-story reinforced concrete (RC) frame structure has been fully investigated through the finite element method. Under obliquely incident SV waves (shear wave in the vertical $x-z$ plane), the distribution of internal forces on the structure in the case of homogeneous foundation soil is significantly asymmetrical. Among the 3 obliquely incident angles investigated in this paper, the maximum inter-story displacement is smallest when the incident angle is $20^{\circ}$ and largest when the angle equals $30^{\circ}$. For the structural fragility, the exceedance probability at each structural damage level is smallest when the incident reflection angle is $20^{\circ}$ and largest when the angle equals $30^{\circ}$. When the structure is located in the silty valley, the influence of oblique incidence is attenuated and there is no obvious stress asymmetry on the structure due to the refraction of seismic waves on the interface.
\end{abstract}

Keywords: soil-structure interaction; fragility analysis; seismic waves; oblique wave incidence; topographic effects; seismic response

\section{Introduction}

In numerical analysis, the rationale for the seismic wave input method directly determines the correctness and accuracy of the output. The traditional input methods mostly utilize the method of uniform consistency. This method supposes that the seismic waves are normally incident shear waves, which means only time characteristics are considered while spatial variation of seismic waves is ignored, notwithstanding the fact that normal incidence is just a special case and oblique incidence is much more common. Jin [1] analyzed 214 different ground seismic records using regression analysis and found that incident angles of seismic waves varied between $45^{\circ}$ and $75^{\circ}$. Following a back analysis of 24 seismic records, Tokimatsu [2] concluded that incident angles were distributed within the range of $12.4^{\circ} \sim 54.1^{\circ}$. In fact, oblique incidence not only significantly influences soil properties [3], but also contributes a lot to the dynamic response of structures. The exclusive consideration of normally incident SV waves will lead to an overestimate of the anti-liquefaction capacity of the foundation soil and the seismic performance of structures. Huang [4] investigated the dynamic response of the Beigongmen metro station under obliquely incident SV waves and found that the axial stresses in columns, the first and second principal stresses at control points on the sidewall all increased as incident angles became larger. Gao [5] studied the dynamic response of a 5-span bridge subjected to oblique seismic waves in detail, and the results showed that when the incident angle was $20^{\circ}$, the shear forces in the bridge piers were more than 3 times greater than the normal incidence case. Therefore it can be concluded that considering obliquely incident seismic waves is of paramount 
importance when analyzing the seismic performance of superstructures. However, it should be mentioned that oblique incidence is still rarely considered in structural seismic fragility analysis.

In the new edition of the seismic ground motion parameter zonation map of China, seismic fortification is mandated for all regions in Zhejiang Province. Jiaxing area is a prosperous and densely populated area located in Zhejiang and is vulnerable to seismic disasters. As a result, the seismic fortification level has been increased from 6 to 7 degrees [6]. Meanwhile, it has become even more urgent to investigate the seismic performance and fragility levels of the local structures while considering the local site and structural characteristics. As depicted in Figure 1, two fault zones near the region of interest are likely to induce earthquake motions, including a possible far-field earthquake originated from the Yangtze river's estuary fault (approximately $140 \mathrm{~km}$ to the site of interest) and a near-field one originated from the Xiaoshan-Qiuchuan fault (approximately $10 \mathrm{~km}$ to the site of interest). The coloured polygons in Figure 1 correspond to the maximum magnitudes of earthquakes that can be induced by different potential earthquake sources in the area. Moreover, deep soft soils and silty valley terrain are widespread in this region. According to Panzera [7], local sites would seriously affect the propagation of seismic waves. Thus the geological features of the Jiaxing area are expected to contribute a lot to the seismic performance of local structures. However, past research about seismic fragility of structures has seldomly considered soil-structure interaction (SSI) since the seismic waves were traditionally applied directly to the foundation. As a result, the local site effects were not reflected in such fragility analyses $[8,9]$.

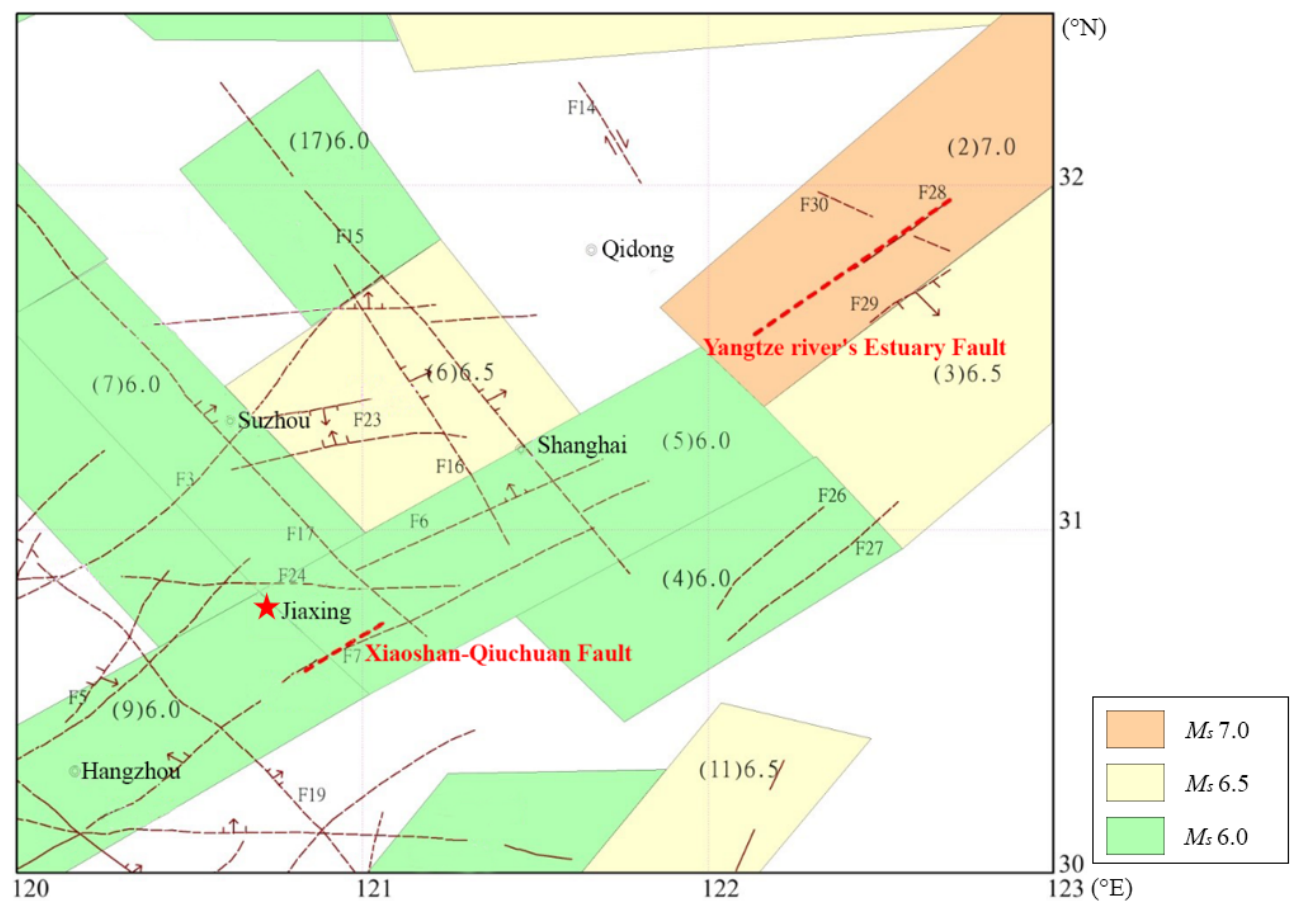

Figure 1. Two fault zones close to the region of interest.

In this paper, the formulae for calculating the equivalent boundary loads on the infinite element boundary for obliquely incident SV waves and P waves (primary waves) are first derived based on the elastic wave theory. By comparing the numerical result with the analytical solution, the validity of the aforementioned input method is proved. Based on the typical site conditions and the seismic fortification requirements in the Jiaxing area, the dynamic response and fragility of a characteristic multi-story frame structure are thoroughly investigated while considering obliquely incident SV waves with different 
incident angles. Consequently, a reliable reference can then be provided for the seismic performance evaluation and strengthening design of local structures.

\section{Model for Analysis}

\subsection{Structural Model}

Jiaxing area has been economically developed for a long time. As a result, there are many relatively old masonry and concrete structures in the local communities. The structural heights generally range from 5 to 7 stories. The foundations are of simple forms, such as strip and mat foundations. To select a representative structure in the local area, the authors first investigated the construction archives from the local urban-rural development bureau and consulted experienced structural engineers. Finally, an $18 \mathrm{~m}$-high, 5-story, 3-span reinforced concrete structure was adopted as the target structure. This structural configuration is quite common for local structures built before 1990 in the Jiaxing area. The corresponding 2D model is depicted in Figure 2. The cross-sectional area of the beam and column were $200 \mathrm{~mm} \times 400 \mathrm{~mm}$ and $600 \mathrm{~mm} \times 600 \mathrm{~mm}$, respectively. The construction materials for both were C30 concrete and HRB335 rebar. A 1.5m-deep strip foundation was adopted as the structural foundation. The floor and roof dead loads were both $7 \mathrm{kN} / \mathrm{m}^{2}$ in the current simulation.

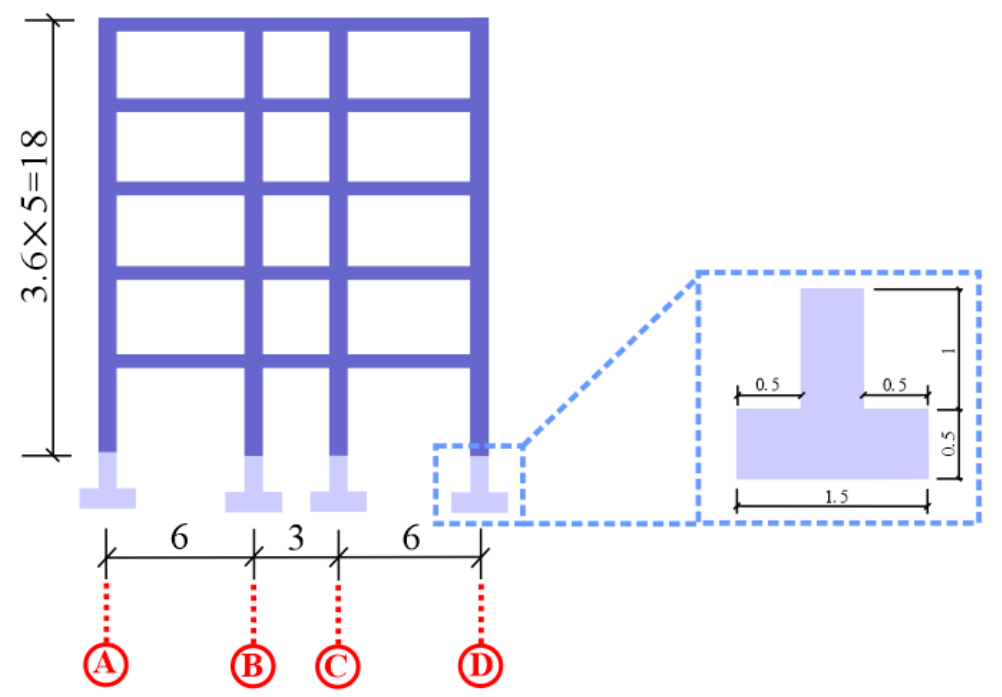

Figure 2. Structural and strip foundation model used in the simulation (unit: $\mathrm{m}$ ).

In the numerical model, the Timoshenko beam element was adopted to model beams and columns of the structure. The corresponding parameters can be found in Table 1. The concrete damage plasticity model [10] was used as the constitutive model for concrete. The relevant parameters include elastic modulus $E_{\mathrm{e}}$, uniaxial compression peak stress $f_{c, r}$, peak strain $\epsilon_{c, r}$, uniaxial tension peak stress $f_{t, r}$ and peak strain $\epsilon_{t, r}$, as listed in Table 1 .

Table 1. Parameters for the concrete plasticity model used in the simulation.

\begin{tabular}{cccccc}
\hline$E_{\boldsymbol{e}}(\mathrm{MPa})$ & $v$ & $f_{c, r}(\mathbf{M P a})$ & $\epsilon_{c, r}$ & $f_{t, r}(\mathbf{M P a})$ & $\epsilon_{t, r}$ \\
\hline $2.2 \times 10^{-4}$ & 0.2 & 3.0 & $1.36 \times 10^{-4}$ & 39.6 & $3.15 \times 10^{-3}$ \\
\hline
\end{tabular}

In order to take account of the tension stiffening effect and the contribution from stirrup, the stress-strain relationship for concrete was modified according to research conducted by Gao [11]. The longitudinal steel bars were simulated through the keyword * rebar in ABAQUS [12]. The 4-node reduced integral plane strain element was adopted to analyze the strip footing. In light of the binding model used by Zhuang [13] to study the interaction between the non-vibrating isolation structure and pile caps, the tie constraints were used to simulate the interaction between the strip footings and column bases. 


\subsection{Foundation Soil Model}

In this study, two types of simplified foundation soil models were examined. The first one represents homogeneous foundation soil, whereas the second one represents a silty valley foundation soil. These two foundation soil types can well capture the typical geological conditions in the Jiaxing area. The homogeneous foundation soil is composed of $100 \mathrm{~m}$-deep silty clay, while the silty valley terrain is the result of the backfilling of river channels and pools, which are widespread in the area. For convenience, the valley terrain was further simplified as a semicircle with a radius of $50 \mathrm{~m}$. This semicircle is filled with mud, as illustrated in Figure 3b.

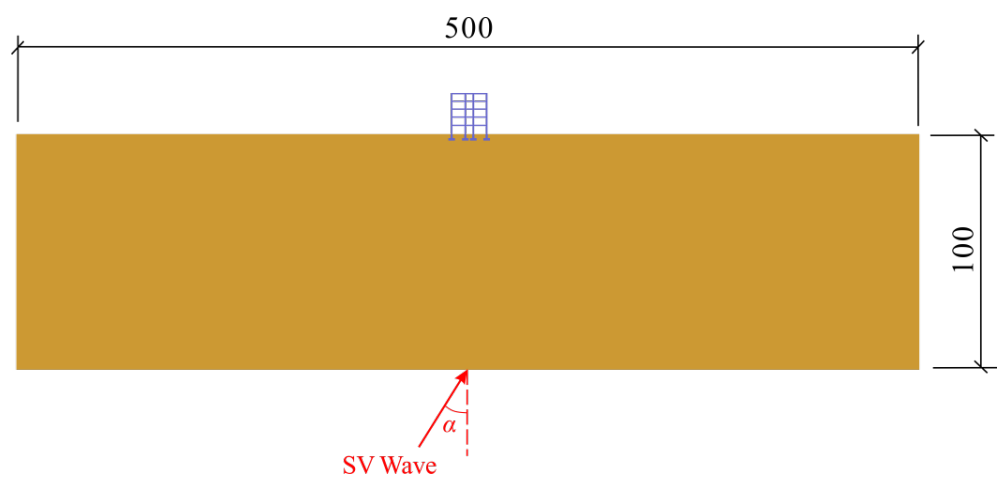

(a)

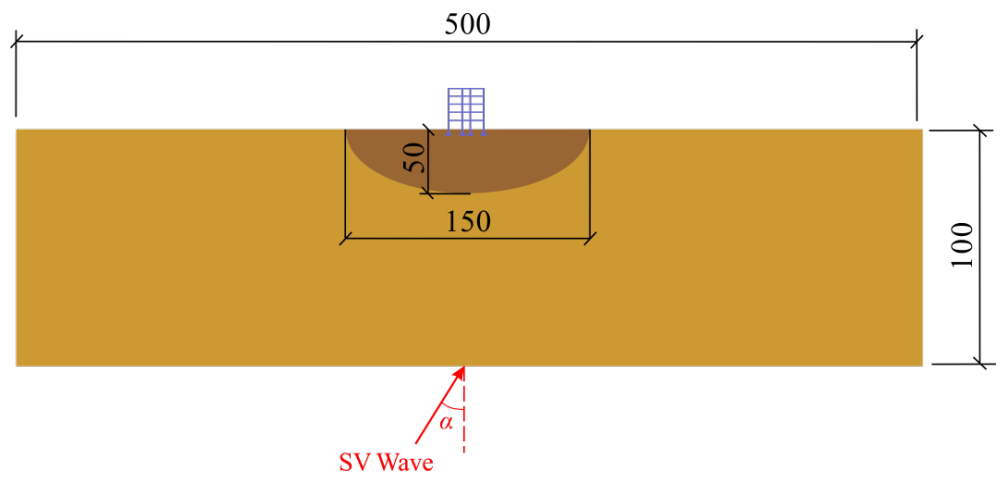

(b)

Figure 3. Soil-structure systems used in the simulation (unit: m): (a) Homogeneous foundation soil model. (b) Silty valley foundation soil model.

In the numerical simulation, the 4-node reduced integral plane strain element (CPE4R) [12] was used to discretize the foundation soil and the Mohr-Coulomb elastoplastic model was adopted as the constitutive relationship [14]. The soil parameters for silty clay and mud are obtained from massive site investigation in the Jiaxing area [15], as shown in Table 2.

Table 2. Soil parameters used in the simulation.

\begin{tabular}{cccccc}
\hline Soil Layer & $\left.\rho \mathbf{( k g} / \mathbf{m}^{\mathbf{3}}\right)$ & $E \mathbf{~ M P a})$ & $v$ & $c(\mathbf{k P a})$ & $\phi\left({ }^{\circ}\right)$ \\
\hline Mud & 1820 & 149 & 0.49 & 5 & 20 \\
Silt clay & 2000 & 329 & 0.49 & 8 & 25 \\
\hline
\end{tabular}




\subsection{Soil-Structure Interface Modeling}

As for the soil-structure interface, the surface-to-surface contact model was adopted to simulate the interaction between strip footings and the foundation soil. The surface with the larger stiffness was chosen as the master surface. Normal behavior was defined as hard contact in the current simulation, which means that normal stress exists if and only if there is no gap between the surfaces. The Coulomb friction model was adopted to simulate the mechanical behavior in the tangential direction. The ultimate shear stress can be expressed in Equation (1):

$$
\begin{gathered}
\tau_{\text {crit }}=\mu p \\
\mu=\tan (0.75 \varphi)
\end{gathered}
$$

where $\mu$ is the friction coefficient between strip footing and foundation soil; $p$ is the normal stress at the surface; $\phi$ represents the internal friction angle of the soil.

\subsection{Soil and Structural Damping}

In nonlinear finite element analysis, Rayleigh damping [16] was adopted to simulate the material damping behavior. The damping matrix is shown in Equation (3).

$$
\mathbf{C}=\alpha_{c} \mathbf{M}+\beta_{c} \mathbf{K}
$$

where $\alpha_{c}$ is the mass-proportional damping coefficient and $\beta_{c}$ is the stiffness-proportional damping coefficient. These two coefficients can be obtained using the method proposed by Hudson [17], as shown in Equations (4) and (5).

$$
\begin{aligned}
\alpha_{c} & =2 \zeta \frac{\omega_{1} \omega_{2}}{\omega_{1}+\omega_{2}} \\
\beta_{c} & =2 \zeta \frac{1}{\omega_{1}+\omega_{2}}
\end{aligned}
$$

where $\omega_{1}$ represents the fundamental frequency of the model; $\omega_{2}=n \omega_{1}$ and $n$ is an odd number greater than $\frac{\omega_{e}}{\omega_{1}} ; \omega_{e}$ is the fundamental frequency of the seismic wave; $\zeta$ represents the damping ratio; Nejati [18] suggested that the damping ratio for soft soil should be $2.6 \%$. $5 \%$ is adopted as the damping ratio for the RC frame structure.

\subsection{Selection of Input Seismic Motions}

In accordance with the aforementioned two possible earthquake sources, both nearfield and far-field earthquakes are likely to happen in the Jiaxing area. However, no strong motion records are available in the area so far. Thus, the seismic motions currently used in the simulation are selected from other existing records. In the seismic motion selection process, the earthquake magnitude $\left(M_{s}\right)$ and the distance $(R)$ from the rupture zone to the site of interest are two main parameters [19]. For near-field earthquakes, since the XiaoshanQiuchuan fault is $10 \mathrm{~km}$ approximately from the site and the $M_{s}$ of induced earthquakes are expected to be around 6 degrees, 13 earthquakes of which $R$ are approximately $10 \mathrm{~km}$ and $M_{s}$ are in the range $4.9 \sim 7.6$ are selected from the Pacific Earthquake Engineering Research Center [20]. For far-field earthquakes, another 5 different seismic waves were selected. The distances of these earthquakes are larger than $25 \mathrm{~km}$ to reduce near-field effects [21]. The spectral accelerations and the characteristic $\left(M_{s}, R\right)$ pairs of the selected seismic motions are plotted in Figure 4. 


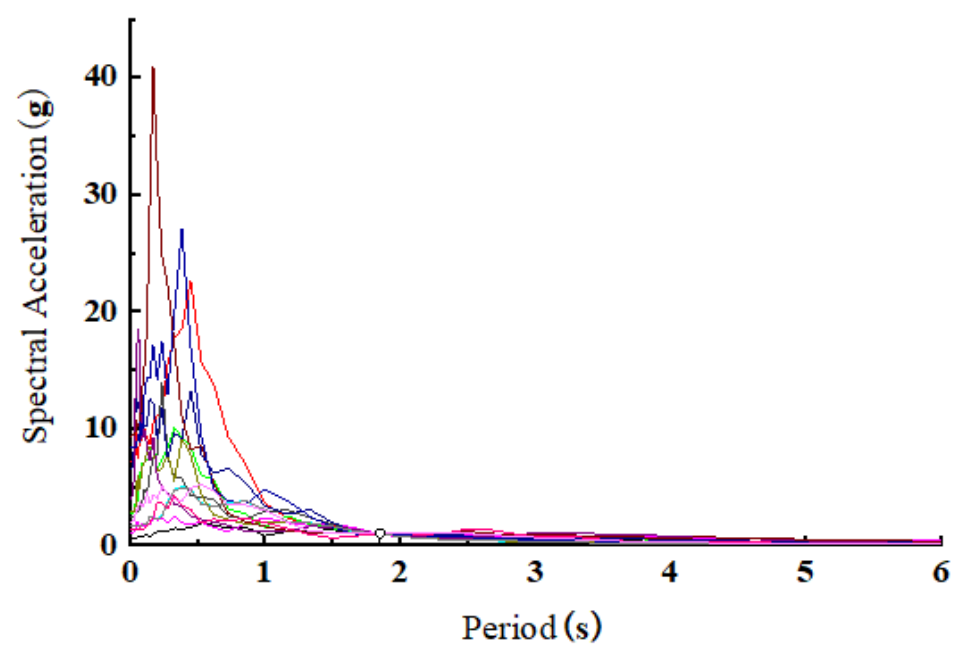

(a)

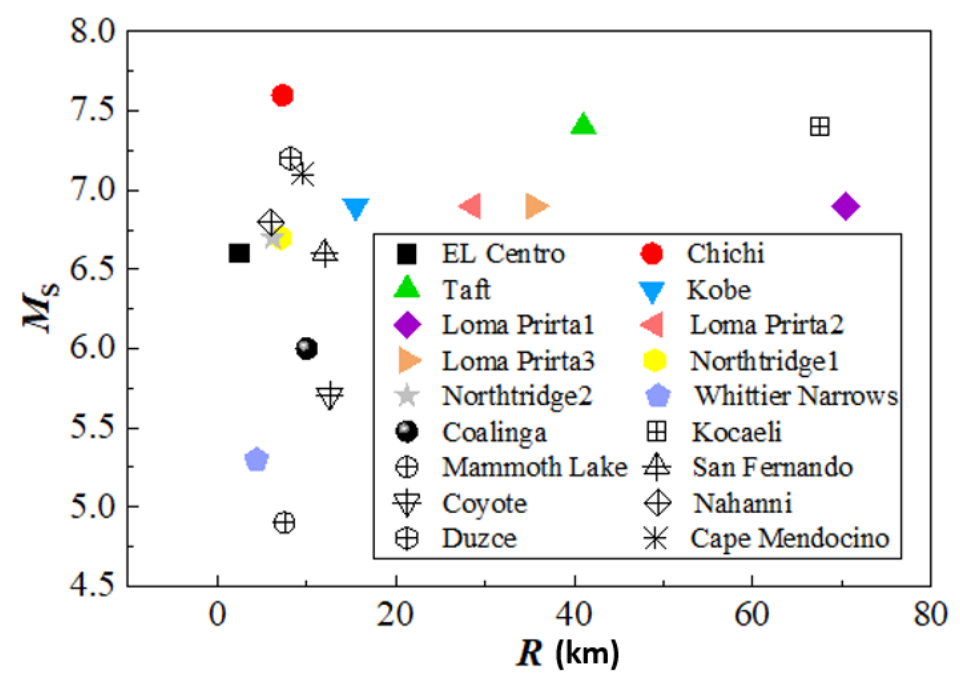

(b)

Figure 4. Details of the 18 selected earthquake motions: (a) Spectral accelerations. (b) $\left(M_{s}, R\right)$ pairs.

\section{Seismic Oblique Incidence on the Infinite Element Boundary}

\subsection{Seismic Oblique Incidence in a Free Field}

As a case of external excitation, the oblique incidence of seismic waves in free field must obey the wave propagation theory. As shown in Figure 5, the SV wave changes its wave mode when reflected by the ground surface. When the SV wave is obliquely incident, the incident angle and the reflection angle must satisfy the Snell's law, as shown in Equation (6). The amplitudes of the reflected SV wave and P wave can be expressed in Equations (7) and (8). 


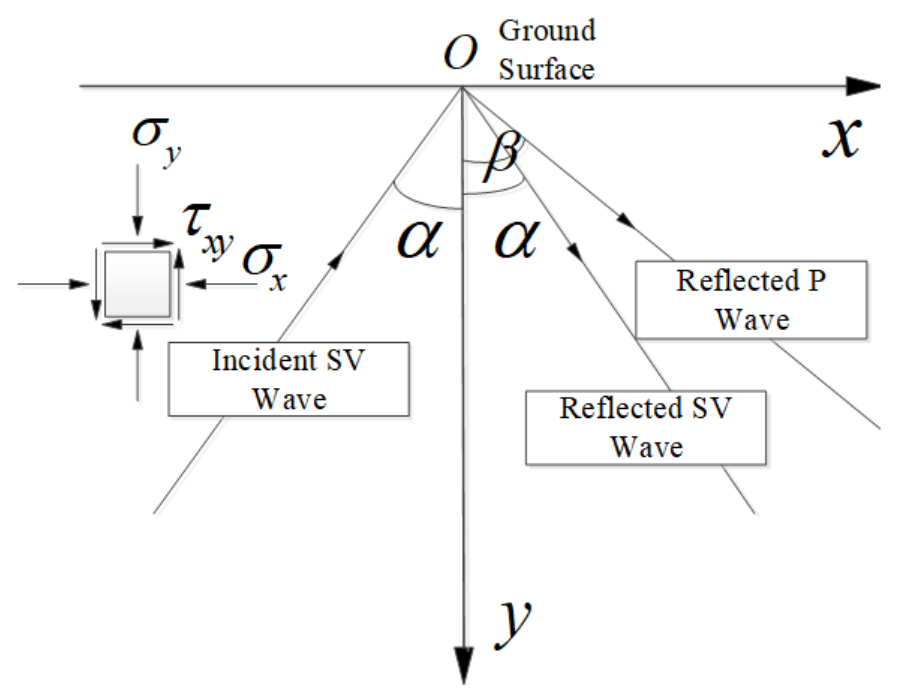

Figure 5. The conversion of wave mode when the SV wave is reflected by the ground surface.

$$
\begin{gathered}
\sin \beta=\frac{c_{p} \sin \alpha}{c_{s}} \\
A_{1}=\frac{-2 c_{p}^{2} \sin 2 \alpha \cos 2 \beta}{c_{s}^{2} \sin 2 \alpha \cos 2 \beta+c_{p}^{2} \cos ^{2} 2 \beta} \\
A_{2}=\frac{c_{s}^{2} \sin 2 \alpha \cos 2 \beta-c_{p}^{2} \cos ^{2} 2 \beta}{c_{s}^{2} \sin 2 \alpha \cos 2 \beta+c_{p}^{2} \cos ^{2} 2 \beta}
\end{gathered}
$$

where $\alpha$ represents the angle of incident and reflected SV waves; $\beta$ represents the reflection angle of P waves; $A_{1}$ represents the amplitude ratio of the reflected SV wave and the incident SV wave; $A_{2}$ represents the amplitude ratio of the reflected $\mathrm{P}$ wave and the incident SV wave.

The case for obliquely incident $\mathrm{P}$ wave is also similar. The reflection angle is shown in Equation (9). The amplitudes of the reflected $\mathrm{P}$ wave and SV wave can be expressed in Equations (10) and (11).

$$
\begin{gathered}
\sin \zeta=\frac{c_{s} \sin \eta}{c_{p}} \\
A_{3}=\frac{\sin \eta \sin 2 \zeta-K^{2} \cos ^{2} 2 \zeta}{\sin \eta \sin 2 \zeta+K^{2} \cos ^{2} 2 \zeta} \\
A_{4}=\frac{-2 \sin 2 \eta \cos 2 \zeta}{\sin 2 \eta \cos 2 \zeta+K^{2} \cos ^{2} 2 \zeta}
\end{gathered}
$$

where $\eta$ represents the angle of incident and reflected $\mathrm{P}$ waves; $\eta$ represents the reflection angle of SV waves; $A_{3}$ represents the amplitude ratio of the reflected $\mathrm{P}$ wave and the incident $\mathrm{P}$ wave while $A_{4}$ represents the amplitude ratio of the reflected SV wave and the incident $P$ wave. Using Equations (6)-(11), the wave field at any point in the foundation soil can be obtained by a superposition of the incident wave field and two reflected wave fields.

\subsection{The Equivalent Loads on the Infinite Element Boundary}

For a fixed boundary, seismic waves will be reflected and generate extra energy in the field of interest, which gives rise to certain errors. Therefore a special artificial boundary is required to avoid this phenomenon. Lysmer [22] proposed a viscous boundary to prevent wave reflection. Liu [23] and Zhao [24] developed a special visco-elastic boundary. In the study reported in this paper, the infinite element implemented in ABAQUS was 
used to absorb the reflected seismic waves. Yang [25] derived the formula to calculate of the equivalent loads on the infinite element boundary for the vertical incidence case, as expressed by Equation (12) for the SV wave and Equation (13) for the P wave.

For the SV wave:

$$
F_{l x}^{-y}(t)=2 A_{l} \rho c_{s} \dot{u}_{s}(t)
$$

For the P wave:

$$
F_{l y}^{-y}(t)=2 A_{l} \rho c_{p} \dot{u}_{p}(t)
$$

In Equations (12) and (13), the superscripts of equivalent force represent the outer normal direction of the infinite element boundary, and the minus sign means the direction is in the negative direction. The subscripts refer to the equivalent force on the $l$-th element. $A_{l}$ refers to the area of the $l$-th element; $\rho$ is the material density; $c_{s}$ is the shear wave velocity; $c_{p}$ is the primary wave velocity; $\dot{u}_{s}$ is the velocity of seismic motions induced by shear waves; $\dot{u}_{p}$ is the velocity of seismic motions induced by primary waves.

Both Equations (12) and (13) include the force components required to overcome the damping of infinite elements and the force of the free field at the finite element boundary. The analysis results in Yang [25] suggest that infinite elements are very efficient in absorbing the reflection energy at the boundary interface. These equations, however, cannot be used for the case of oblique incidence seismic waves.

By using the concept of wave fronts, the problem of oblique incidence can be equivalent to normal incidence on the wave front. As a result, the differential input on the boundary can be transformed into a uniform excitation problem. For example, for the obliquely incident SV wave, as shown in Figure 6, SV wave is incident from the lower left side of the model at an angle of $\alpha$ with respect to the vertical direction, as depicted in Figure 7. The time variable $t$ is defined as 0 when the wave reaches the lower left corner of the model. The total wave field on the artificial boundary can be decomposed into an internal field and an external field. The external field can be simulated via the infinite element boundary. The internal field on the boundary is depicted in Figure 6, in which the field on the left boundary is a free field composed of the incident SV wave, reflected SV wave and reflected $P$ wave while on the lower boundary the incident $S V$ wave is considered exclusively. Note that no internal field exists on the right boundary.

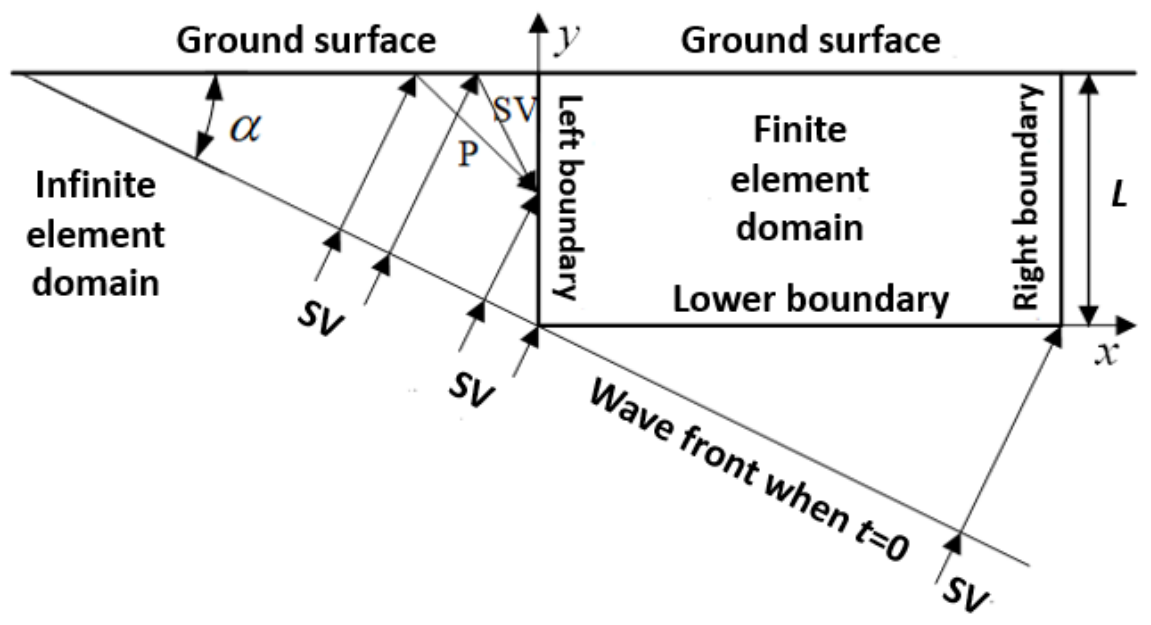

Figure 6. Wave fields on the artificial boundary with oblique incidence of SV waves. 


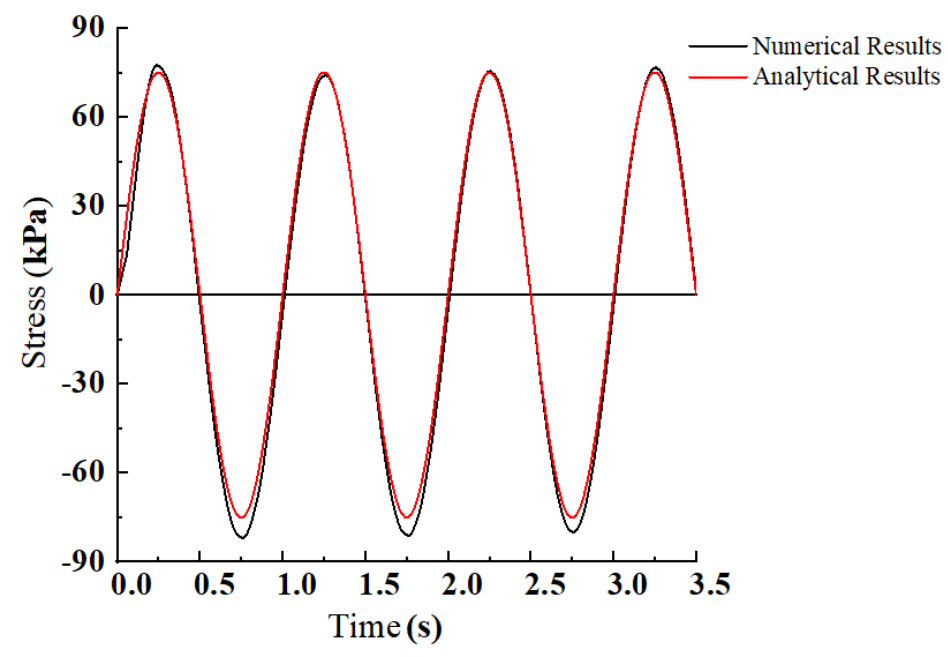

Figure 7. Comparison of the analytical and simulated shear stress-time series at the central point of the ground surface.

The equivalent nodal force associated with the incident SV wave on the infinite element boundary can then be calculated based on the elastic wave equation. The nodal force is composed of two components, i.e., the nodal force resisting the damping of the infinite element boundary and the nodal force resisting the near-field media. The formulae are listed below.

For the lower boundary:

$$
\begin{gathered}
F_{l x}^{-y}(t)=-A_{l} G \cos 2 \alpha \frac{\dot{u}_{s}\left(t-\Delta t_{4}\right)}{c_{s}}+A_{l} \rho c_{s} \dot{u}_{s}\left(t-\Delta t_{4}\right) \cos \alpha \\
F_{l y}^{-y}(t)=A_{l} G \sin 2 \alpha \frac{\dot{u}_{s}\left(t-\Delta t_{4}\right)}{c_{S}}+A_{l} \rho c_{p} \dot{u}_{s}\left(t-\Delta t_{4}\right) \sin \alpha
\end{gathered}
$$

For the left boundary:

$$
\begin{aligned}
& F_{l x}^{-x}(t)= A_{l}\left\{\frac{G}{c_{s}} \sin 2 \alpha\left[\dot{u}_{s}\left(t-\Delta t_{1}\right)-A_{1} \dot{u}_{s}\left(t-\Delta t_{2}\right)\right]+\frac{\left(\lambda+2 G \sin ^{2} \beta\right)}{c_{p}} A_{2} \dot{u}_{s}\left(t-\Delta t_{3}\right)+\right. \\
&\left.\rho c_{p}\left[\dot{\boldsymbol{u}}_{s}\left(t-\Delta t_{1}\right) \cos \alpha+A_{1} \dot{u}_{s}\left(t-\Delta t_{2}\right) \cos \alpha+A_{2} \dot{u}_{s}\left(t-\Delta t_{3}\right) \sin \beta\right]\right\} \\
& F_{l y}^{-x}(t)= A_{l}\left\{\frac{G}{c_{s}} \cos 2 \alpha\left[A_{1} \dot{u}_{s}\left(t-\Delta t_{2}\right)-\dot{u}_{s}\left(t-\Delta t_{1}\right)\right]-\frac{G \sin 2 \beta}{c_{p}} A_{2} \dot{u}_{s}\left(t-\Delta t_{3}\right)+\right. \\
&\left.\rho c_{s}\left[\dot{u}_{s}\left(t-\Delta t_{1}\right) \sin \alpha-A_{1} \dot{u}_{s}\left(t-\Delta t_{2}\right) \sin \alpha+A_{2} \dot{u}_{s}\left(t-\Delta t_{3}\right) \cos \beta\right]\right\}
\end{aligned}
$$

where $\Delta t_{1}, \Delta t_{2}$ and $\Delta t_{3}$ are the time lags of the incident SV wave, reflected SV wave and reflected $\mathrm{P}$ wave on the left boundary, respectively. $\Delta t_{4}$ is the time lag of the incident $\mathrm{SV}$ wave on the lower boundary, as shown in Equations (18)-(21).

$$
\begin{gathered}
\Delta t_{1}=\frac{y \cos \alpha}{c_{s}} \\
\Delta t_{2}=\frac{(2 L-y) \cos \alpha}{c_{s}} \\
\Delta t_{3}=\frac{(L-y) \cos \beta}{c_{p}}+[L-(L-y) \tan \alpha \tan \beta] \frac{\cos \alpha}{c_{s}}
\end{gathered}
$$




$$
\Delta t_{4}=\frac{x \sin \alpha}{c_{s}}
$$

In the case of oblique incidence of the $\mathrm{P}$ wave, the equivalent nodal force on the lower boundary is shown in Equations (22) and (23).

$$
\begin{gathered}
F_{l x}^{-y}(t)=A_{l} G \sin 2 \eta \frac{\dot{u}_{p}\left(t-\Delta t_{8}\right)}{c_{p}}+A_{l} \rho c_{s} \dot{u}_{p}\left(t-\Delta t_{8}\right) \sin \eta \\
F_{l y}^{-y}(t)=A_{l}\left(\lambda+2 G \cos ^{2} \eta\right) \frac{\dot{u}_{p}\left(t-\Delta t_{8}\right)}{c_{p}}+A_{l} \rho c_{p} \dot{u}_{p}\left(t-\Delta t_{8}\right) \cos \eta
\end{gathered}
$$

For the left boundary:

$$
\begin{aligned}
F_{l x}^{-x}(t)= & A_{l}\left\{\frac{\lambda+2 G \sin ^{2} \eta}{c_{p}}\left[\dot{u}_{p}\left(t-\Delta t_{5}\right)+A_{3} \dot{u}_{p}\left(t-\Delta t_{6}\right)\right]+\rho c_{s} \sin 2 \zeta A_{4} \dot{u}_{p}\left(t-\Delta t_{7}\right)+\right. \\
& \left.\rho c_{p}\left[\dot{u}_{p}\left(t-\Delta t_{5}\right) \cos \eta+A_{3} \dot{u}_{p}\left(t-\Delta t_{6}\right) \sin \eta+A_{4} \dot{u}_{p}\left(t-\Delta t_{7}\right) \cos \zeta\right]\right\} \\
F_{l y}^{-x}(t)= & A_{l}\left\{\frac{G}{c_{p}} \sin 2 \eta\left[\dot{u}_{p}\left(t-\Delta t_{5}\right)-A_{3} \dot{u}_{p}\left(t-\Delta t_{6}\right)\right]+\rho c_{s} \cos 2 \zeta A_{4} \dot{u}_{p}\left(t-\Delta t_{7}\right)+\right. \\
& \left.\rho c_{s}\left[\dot{u}_{p}\left(t-\Delta t_{5}\right) \cos \eta-A_{3} \dot{u}_{p}\left(t-\Delta t_{6}\right) \cos \eta+A_{4} \dot{u}_{p}\left(t-\Delta t_{7}\right) \cos \zeta\right]\right\}
\end{aligned}
$$

where $\Delta t_{5}, \Delta t_{6}$ and $\Delta t_{7}$ are the time lags of the incident SV wave, reflected SV wave and reflected $\mathrm{P}$ wave on the left boundary, respectively. $\Delta t_{8}$ is the time lag of the incident SV wave on the lower boundary, as shown in Equations (26)-(29).

$$
\begin{gathered}
\Delta t_{5}=\frac{y \cos \eta}{c_{p}} \\
\Delta t_{6}=\frac{(2 L-y) \cos \eta}{c_{p}} \\
\Delta t_{7}=\frac{(L-y) \cos \zeta}{c_{s}}+[L-(L-y) \tan \eta \tan \zeta] \frac{\cos \eta}{c_{p}} \\
\Delta t_{8}=\frac{x \sin \eta}{c_{p}}
\end{gathered}
$$

In this paper, only the case of SV oblique incidence is verified due to the length limitation. It should be noted that there exists a critical incident angle $\alpha_{c}$, which is related to the propagation of an SV wave, as shown in Equation (30).

$$
\alpha_{c}=\arcsin \left(\frac{c_{\mathrm{s}}}{c_{\mathrm{p}}}\right)=\arcsin \left(\sqrt{\frac{1-2 v}{2(1-v)}}\right)
$$

where $c_{s}$ represents the SV wave velocity; $c_{p}$ represents the P wave velocity; $v$ is the Poisson's ratio of the soil. When the incident angle $\alpha$ is smaller than $\alpha_{c}$, a reflected SV wave and a P wave can be generated. When $\alpha>\alpha_{c}$, only the reflected SV wave is generated. Due to the fact that the density of soil increases with depth, the incident angle of seismic waves propagating to the ground surface from the deep part of the foundation gradually decreases according to the laws of refraction and reflection. Hence only $\alpha<\alpha_{c}$ is considered in this paper [4].

In order to verify the reliability equivalent nodal force formulae, the numerical method described in this paper was compared with the analytical solution [26]. In the numerical model, the foundation soil model has a width of $500 \mathrm{~m}$ and a depth of $100 \mathrm{~m}$. The soil is assumed to be elastic, with a density of $2000 \mathrm{~kg} / \mathrm{m}^{3}$, a Poisson's ratio of 0.3 , an elastic modulus of $208 \mathrm{MPa}$, a critical incident angle of $32.31^{\circ}$ and a shear wave velocity of 
$200 \mathrm{~m} / \mathrm{s}^{2}$. The SV wave has a frequency of $1 \mathrm{~Hz}$ and an amplitude of 1 . The angle of incidence is $30^{\circ}$. The dynamic shear stress-time series at the central point of the ground surface, calculated in two different ways, are depicted in Figure 7. It can be observed that the horizontal stress calculated by the method proposed in this paper agrees well with the analytical solution in terms of the period and amplitude, indicating the method proposed in this paper is highly accurate.

\section{Dynamic Response of Multi-Story RC Frame Structures Subjected to Obliquely Incident Seismic Waves}

In order to compare dynamic responses of multi-story RC structures under incident SV waves with different incident angles, a series of SV waves with the same amplitude but different incident angles were used in the simulation. The amplitudes for these SV waves are $0.1 \mathrm{~g}$. Although the seismic response of the superstructure is expected to vary under different SV waves with different incident angles qualitatively, calculating all possible oblique incident waves with $\alpha<\alpha_{c}$ is extremely arduous and time-consuming. As a result, with the aim to foreground such influences quantitatively, the incident angles used in the simulation were $0^{\circ}, 10^{\circ}, 20^{\circ}$ and $30^{\circ}$, respectively. Moreover, to highlight the influence of topographic effects on the oblique incidence, the dynamic structural responses for the case of homogeneous foundation soil and silty valley foundation soil were also compared.

\subsection{The Influence of Oblique Incidence of SV Waves on the Column}

Table 3 shows the peak shear force at the top and bottom of columns A, B, C and D in the cases of homogenous foundation soil and silty valley foundation soil. With the increase of incident angle, the peak shear force at the top of each column first decreases and then increases. The shear force variation tendency at the bottom of each column is consistent with the top one. In the case of homogenous soft soil, columns A and B on the left of the structure have larger peak shear forces than their counterparts $D$ and $C$. The peak shear force in column B (A) is 1.38 (2.2) times as large as in C (D). Hence the distribution of the shear force at the bottom of the column is significantly asymmetrical. However, for the silty valley case, the degree of asymmetry is not large and is independent of the incident angle of SV waves. This is because the valley terrain has topographic effects [27] and changes the direction of wave propagation on the interface. Therefore the superstructure is more evenly stressed. In the meantime, it should be noted that the peak shear force in the case of the silty valley foundation soil is larger than that in the case of homogeneous soil, which is the result of the valley focusing effects [28]. Gao [5] observed a similar situation when analyzing the influence of valley focusing effects on the seismic resistance of bridge piers. He found that the dynamic response of the piers was amplified significantly when the incident angle of the SV wave is between $0^{\circ}$ and $30^{\circ}$.

Table 3. Peak shear force on each column in different foundation soil under the Coyote wave (unit: $\mathrm{kN}$ ).

\begin{tabular}{|c|c|c|c|c|c|c|c|c|c|}
\hline \multirow{2}{*}{ Foundation Soil } & \multirow{2}{*}{ Incident Angle } & \multicolumn{2}{|c|}{ Column A } & \multicolumn{2}{|c|}{ Column B } & \multicolumn{2}{|c|}{ Column C } & \multicolumn{2}{|c|}{ Column D } \\
\hline & & Top & Bottom & Top & Bottom & Top & Bottom & Top & Bottom \\
\hline \multirow{4}{*}{ Homogenous } & $\alpha=0^{\circ}$ & 1.110 & 6.204 & 4.879 & 7.562 & 4.875 & 6.418 & 1.084 & 4.921 \\
\hline & $\alpha=10^{\circ}$ & 1.005 & 6.038 & 3.380 & 7.208 & 3.603 & 6.107 & 0.546 & 4.498 \\
\hline & $\alpha=20^{\circ}$ & 0.569 & 4.175 & 3.152 & 4.216 & 3.749 & 3.950 & 0.826 & 3.327 \\
\hline & $\alpha=30^{\circ}$ & 0.884 & 7.796 & 3.560 & 7.756 & 3.572 & 5.605 & 1.083 & 3.522 \\
\hline \multirow{4}{*}{ Silty valley } & $\alpha=0^{\circ}$ & 1.542 & 6.875 & 6.088 & 7.494 & 6.017 & 6.847 & 1.497 & 6.384 \\
\hline & $\alpha=10^{\circ}$ & 1.301 & 7.753 & 4.887 & 8.171 & 4.929 & 6.311 & 1.009 & 5.426 \\
\hline & $\alpha=20^{\circ}$ & 1.077 & 5.196 & 4.153 & 6.117 & 3.635 & 6.123 & 1.100 & 4.984 \\
\hline & $\alpha=30^{\circ}$ & 1.381 & 7.632 & 4.479 & 7.641 & 4.118 & 8.103 & 1.417 & 7.133 \\
\hline
\end{tabular}

\subsection{The Influence of Obliquely Incident SV-Waves on the Displacement of Each Story}

In Figure $8 \mathrm{a}, \mathrm{b}$, the maximum inter-story displacement of each story under the influence of the Coyote wave is depicted. It is evident that in both homogeneous soil and silty 
valley cases, the maximum inter-story displacement occurs on the first floor and decreases for other higher stories. This phenomenon agrees well with the structural deformation observed during Wenchuan Earthquake [29]. Moreover, the maximum inter-story displacement in the case of silty valley foundation soil is larger than the homogeneous foundation soil. When the seismic wave is normally incident, the slopes of the curves in Figure $8 \mathrm{a}, \mathrm{b}$ are almost identical, which indicates that the maximum inter-story displacement of each story is distributed in a uniform way. When the SV wave is obliquely incident, it appears that the slope of the lower part of the curve is larger than the upper part, indicating that the oblique incidence of the seismic wave aggravates the inter-story displacement. Among all the three different incident angles investigated in this paper, the maximum inter-story displacement is smallest when the incident angle is $20^{\circ}$. When the incident angle is $30^{\circ}$, the maximum inter-story displacements on the higher stories is smaller than that in the case of vertical incidence. However, the maximum inter-story displacement at the lower story has a contrary tendency.

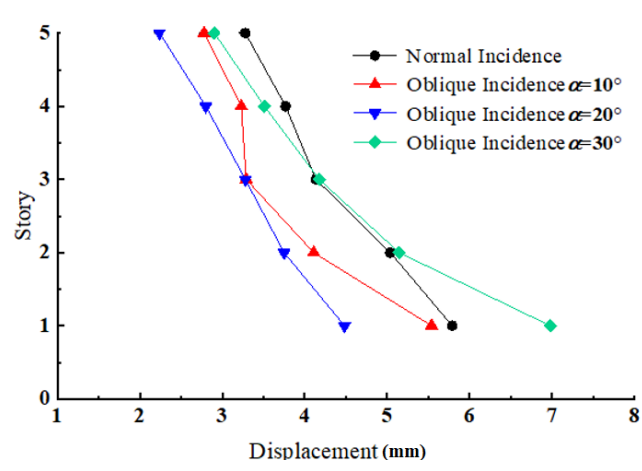

(a)

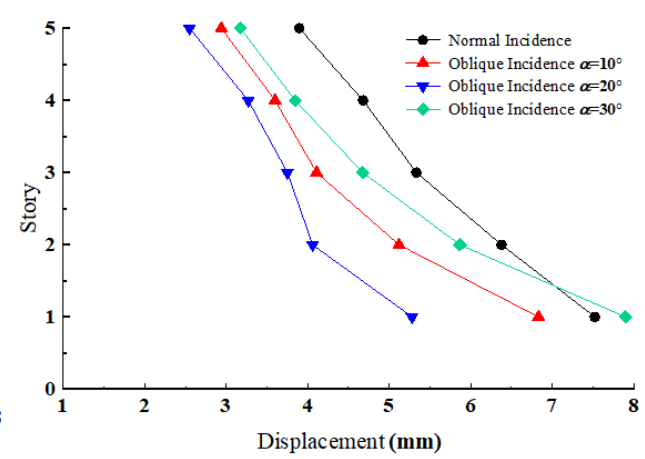

(b)

Figure 8. The distribution of maximum inter-story displacement along the height under the obliquely incident Coyote wave: (a) Homogenous foundation soil case. (b) Silty valley foundation soil case.

\section{Fragility Analysis of Multi-Story RC Frame Structures under Obliquely Incident Seismic Waves}

\subsection{The Method of Fragility Analysis}

According to Code for Seismic Design of Buildings (GB50011-2010) [30], the structural damage level is divided into five sections, i.e., perfect, slight damage, moderate damage, severe damage and collapse. The corresponding threshold values for these intervals are denoted as $L S_{1}, L S_{2}, L S_{3}$ and $L S_{4}$. In this paper, the maximum drift is adopted as the index for structural seismic performance. In the current code in China, the 4 threshold values for $R C$ structures are defined as $L S_{1}=\frac{1}{500}, L S_{2}=\frac{1}{250}, L S_{3}=\frac{1}{120}$ and $L S_{4}=\frac{1}{60}$ respectively.

The current seismic fortification intensity for the Jiaxing area is $6 \sim 7$ degrees. According to the relationship between the seismic fortification intensity and peak ground acceleration(PGA), as specified in the Code of Seismic Design of Buildings [30], 18 different seismic waves were modulated with 5 different PGAs: namely $0.05 \mathrm{~g}, 0.1 \mathrm{~g}, 0.2 \mathrm{~g}, 0.3 \mathrm{~g}$, and $0.4 \mathrm{~g}$. Together with 2 foundation soil types and 4 incident angles, a total of 720 seismic wave cases were generated to build up the database.

In fragility analysis, it is generally assumed that inter-story drift follows a lognormal distribution for seismic waves of identical PGAs [31].

$$
\ln \theta_{\max } \sim N\left(\mu_{\ln \theta_{\max }}, \sigma_{\ln \theta_{\max }}^{2}\right)
$$

where $\mu_{\ln \theta_{\max }}$ and $\sigma_{\ln \theta_{\max }}$ are the logarithms of the mean value and the standard deviation of the inter-story drifts, respectively. 
The failure probability $P\left(\theta_{\max } \mid P G A>L S_{i}\right)$ of the structure can be expressed in Equation (32).

$$
P\left(\theta_{\max } \mid P G A>L S_{i}\right)=1-\Phi\left(\frac{\ln \left(L S_{i}\right)-\mu_{\ln \theta_{\max } \mid P G A}}{\sigma_{\ln \theta_{\max } \mid P G A}^{2}}\right)
$$

where $\mu_{\ln \theta_{\max }}$ and $\sigma_{\ln \theta_{\max }}$ are derived from time history analysis; $L S_{i}$ represents the corresponding threshold values of the structural damage levels; $\Phi($ ) represents the standard normal distribution function.

As discussed above, through probability and statistical analyses, the exceedance probability for each model with different PGAs can be obtained. The data points are then depicted with PGA as the abscissa and the exceedance probability as the ordinate. The corresponding seismic fragility curve can finally be derived.

\subsection{The Influence of Oblique Incidence of SV Waves on the Seismic Fragility of Structures}

The seismic fragility curves for the structures located on the homogeneous soft foundation soil and the silty valley foundation soil are depicted in Figures 9 and 10, respectively. The subgraphs (a), (b), (c), and (d) correspond to the 4 different levels of structural performance, respectively. It can be observed from the figures that the variation trends of the fragility curves for the two foundation models are almost identical. Nevertheless, the deformation of the structure built on the valley terrain has been magnified due to the topographic effects [5]. As a result, structures are more susceptible to destruction in this case. Thus the exceedance probability for structures built upon on the silty valley foundation soil is overall higher than for structures located on the homogenous soil.

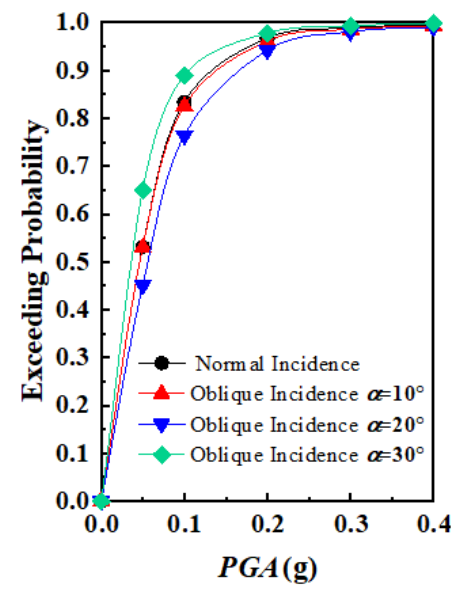

(a)

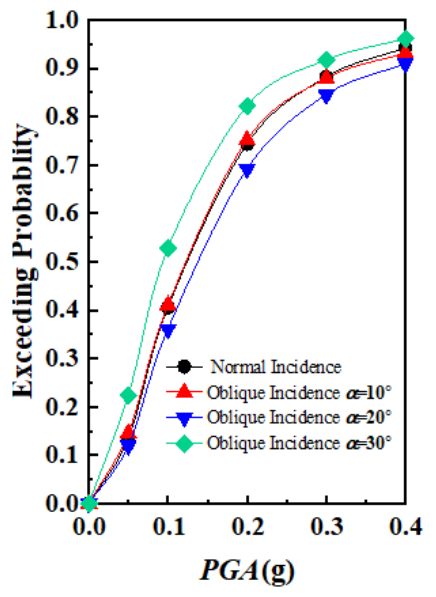

(b)

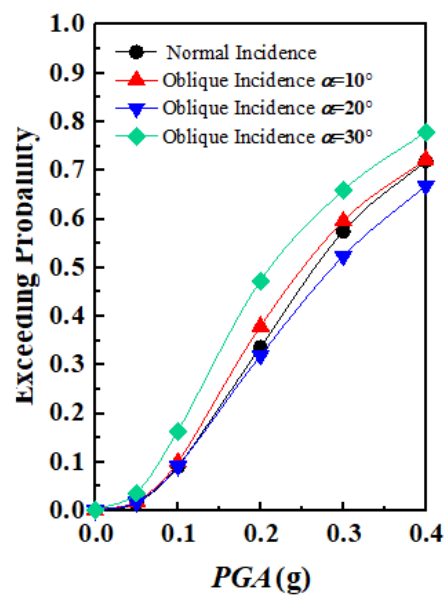

(c)

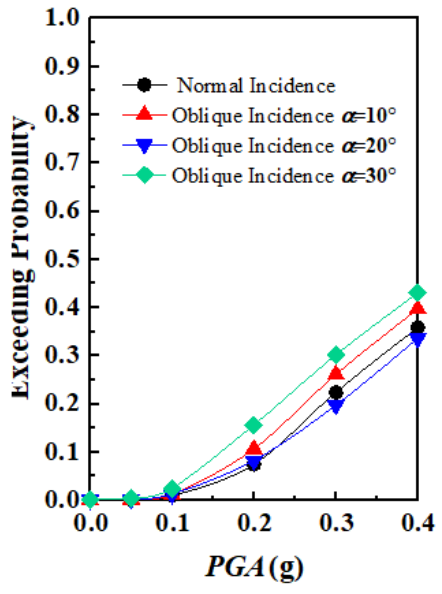

(d)

Figure 9. The seismic fragility curves of homogeneous foundation soil model at different seismic damage levels: (a) Slight demage (b) Moderate damage (c) Severe damage (d) Collapse.

At each damage level, there seems to be a significant correlation between the structural fragility and the incident angles. Among the 4 incident angles investigated, the exceedance probability is smallest when the incident angle is $20^{\circ}$ and largest when the incident angle is $30^{\circ}$, indicating that the structure is most vulnerable in the latter situation. In order to analyze the influence of obliquely incident seismic waves on the fragility of structures at a deeper level, the differences in exceedance probabilities between normally incident and obliquely incident waves were obtained for 3 different incident angles, as shown in Figures 11 and 12. It is quite evident that the variation trends with respect to PGA for the two foundation models are quite similar. The observed differences only depend on the incident angle of seismic waves. When the incident angle is $10^{\circ}$, the corresponding 
exceedance probabilities at each damage level are almost identical to the case of normal incidence. The exceedance probabilities for each damage level reduce when the incident angle is $20^{\circ}$ but tend to be magnified when the incident angle is $30^{\circ}$. For the silty valley model, the amplification effects at the levels of slight damage and severe damage are smaller than the case for the homogenous soil model. The amplification effect, however, is rather obvious at the level of moderate damage, with a 14\% larger maximum damage probability. Consequently, it is of paramount importance to consider the influence of obliquely incident seismic waves at the level of moderate damage when analyzing the fragility of structures.

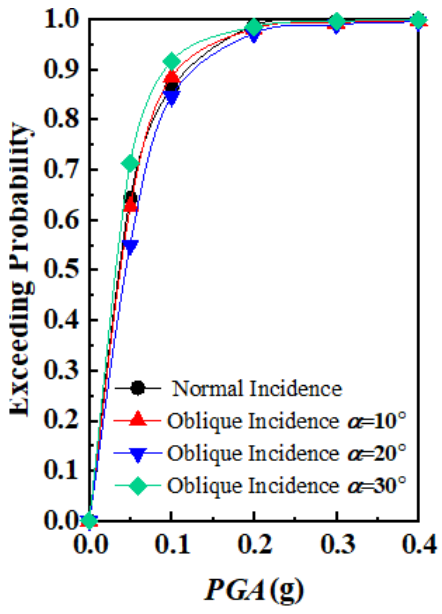

(a)

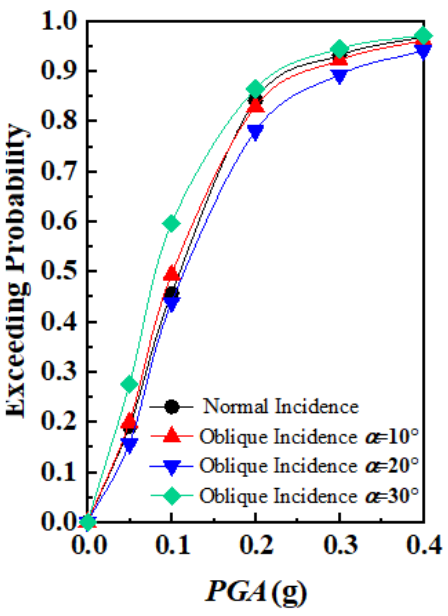

(b)

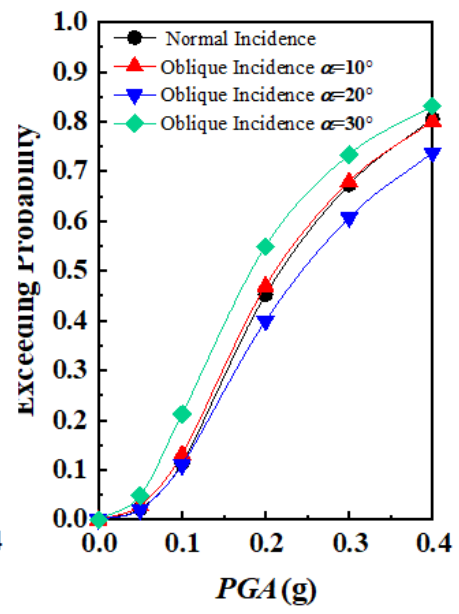

(c)

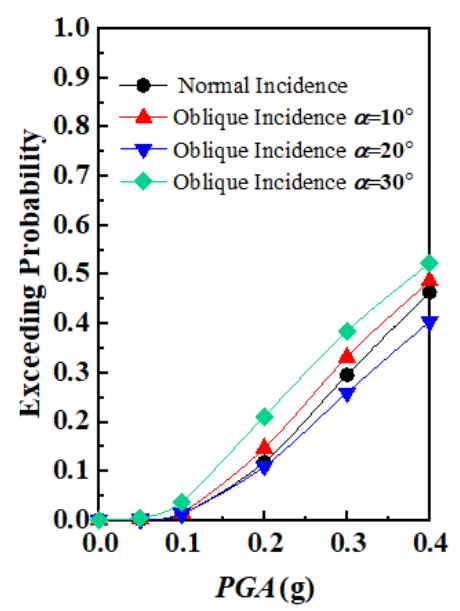

(d)

Figure 10. The seismic fragility curves of silty valley model at different seismic damage levels: (a) Slight demage (b) Moderate damage (c) Severe damage (d) Collapse.

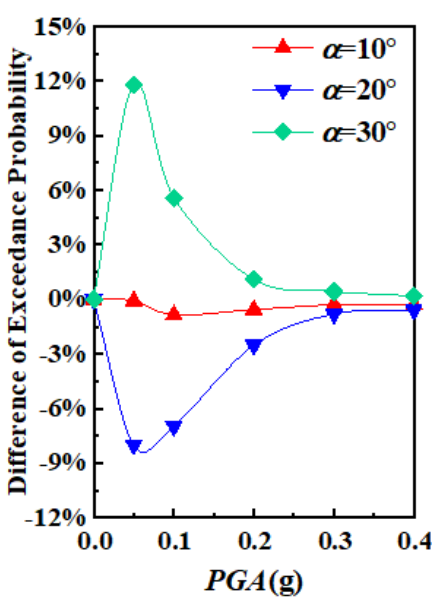

(a)

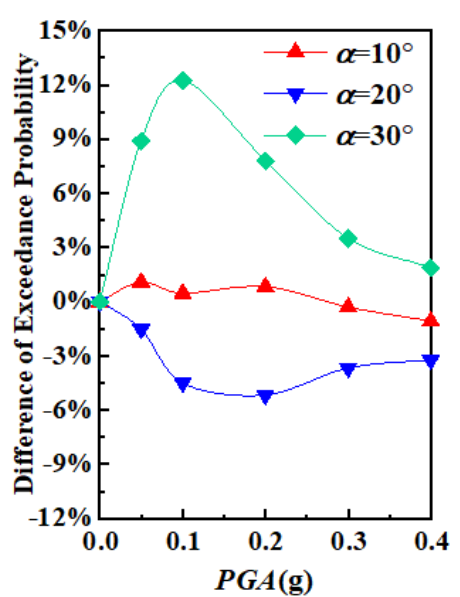

(b)

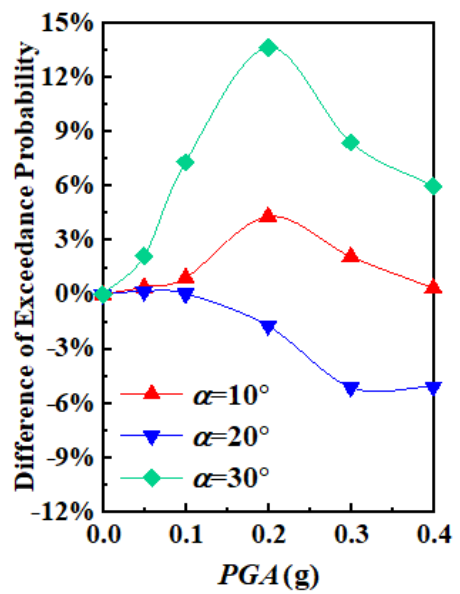

(c)

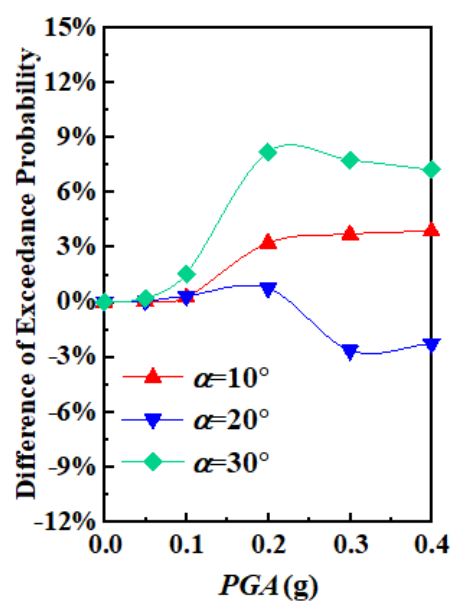

(d)

Figure 11. Differences of exceedance probability between the normal incidence and the oblique incidences at different seismic damage levels in the case of homogenous foundation soil: (a) Slight demage (b) Moderate damage (c) Severe damage (d) Collapse. 


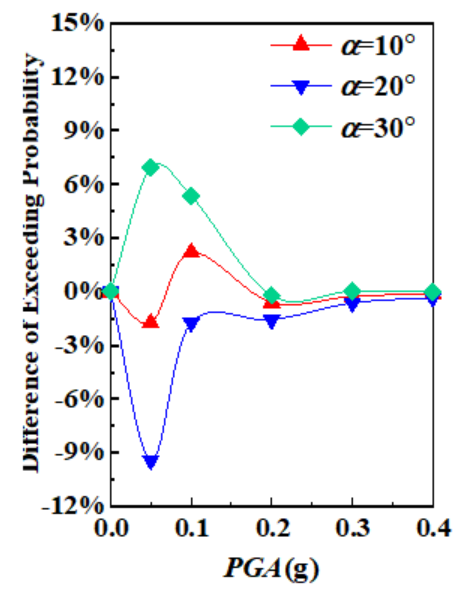

(a)

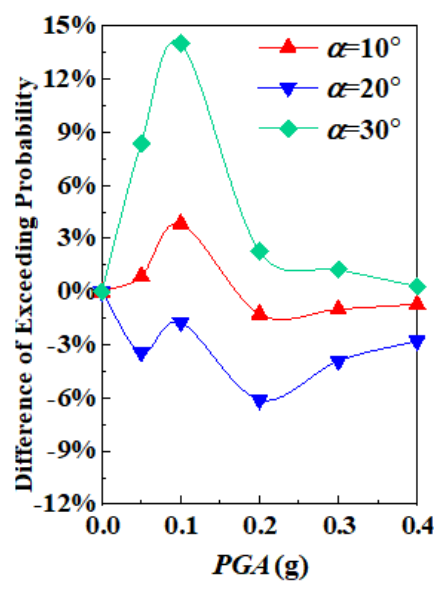

(b)

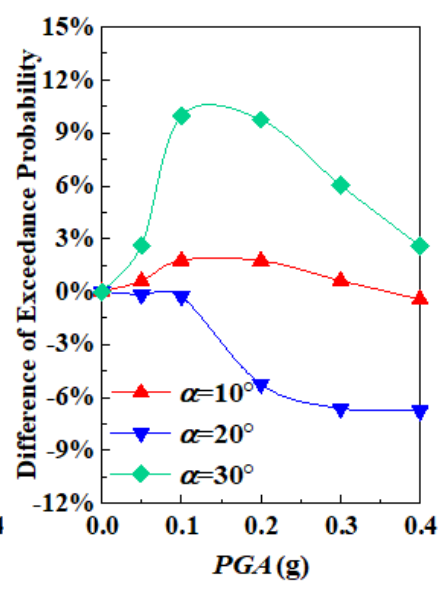

(c)

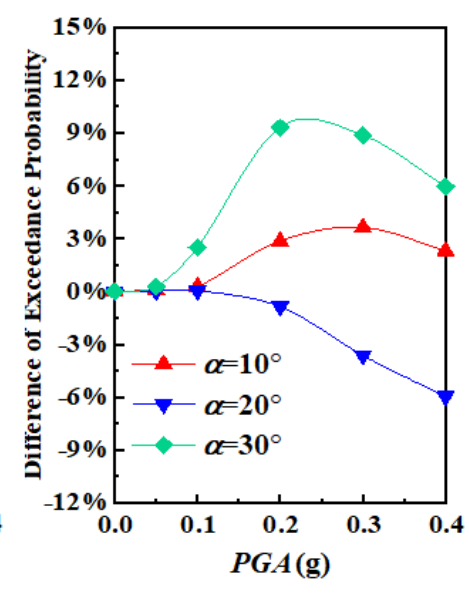

(d)

Figure 12. Differences of exceedance probability between the normal incidence and the oblique incidences at different seismic damage levels in the case of silty valley foundation soil: (a) Slight demage (b) Moderate damage (c) Severe damage (d) Collapse.

The abovementioned detrimental effects of oblique incidence were also observed in other relevant research. For instance, Cen [32] concluded that the increase of incident angle could lead to larger seismic response of the dam. Gao [5] studied the seismic performance of bridges and concluded that the structure was more fragile when the incident angle of SV waves was $30^{\circ}$. Lyu [33] investigated the influence of oblique SV waves on the underground tunnel and largest seismic response was observed when the incident angle equaled $30^{\circ}$. Wang [34] systematically analyzed the dynamic performance of an underground powerhouse and the structural damage reached the maximum when the incident angle was $30^{\circ}$. $\mathrm{Li}$ [35] studied the site response under obliquely incident seismic waves and found that earthquake-induced internal force had the largest magnitude when the SV wave was obliquely incident at $30^{\circ}$. These results are consistent with those reported in this paper. However, it should be noted that previous research seldom considered the influence of oblique incidence on the fragility of superstructures. Furthermore, this equivalent load method proposed previously is based on the infinite element, which has already been implemented in ABAQUS. Therefore, this method is believed to be easily applicable in engineering practice.

\section{Conclusions}

In this paper, the infinite element is used to absorb the reflected wave at the boundary, and the equivalent load formulae for obliquely incident seismic waves are derived. Two numerical models were established based on local topography, geological conditions and seismic fortification requirement of the Jiaxing Area. The dynamic responses of multi-story structures subjected to obliquely incident seismic waves have been thoroughly investigated. From the results, it can be concluded that obliquely incident seismic waves have a nonnegligible influence on the dynamic response of structures, as stated below.

- For homogenous foundation soil, the internal force distribution within the structure is significantly asymmetrical, i.e., shear forces on the columns close to the seismic source are much larger than those far from the seismic source.

- Among the 4 specific different incident angles investigated in the case of homogenious foundation soil, the maximum inter-story displacement is smallest when the incident angle is $20^{\circ}$ and largest when the incident angle is $30^{\circ}$. Moreover, this rule also applies to the fragility of structures. At each structural damage level, the exceedance probability is smallest when the incident angle is $20^{\circ}$ and largest when $30^{\circ}$. 
- For silty valley foundation, there is no obvious asymmetry of internal force distribution since the reflection and refraction of seismic waves at the terrain interface attenuate the influence of obliquely incident seismic waves. However, the valley terrain does magnify the dynamic response of the superstructure. Moreover, the fragility of structures built on a silty valley foundation soil is strongly influenced by the incident angles, particularly at the moderate damage level.

Author Contributions: Conceptualization, B.H. and Y.Z.; methodology, B.H.; software, J.G.; validation, B.H.and K.L.; formal analysis, J.G.; investigation, J.G.; resources, Y.Z.; data curation, K.L.; writing — original draft preparation, J.G. and K.L.; writing—review and editing, J.G.; visualization, J.G.; supervision, B.H.; project administration, Y.Z.; funding acquisition, Y.Z. All authors have read and agreed to the published version of the manuscript.

Funding: This research was funded by the the National Natural Science Foundation of China, grant number 51988101 and Provincial Key Research and Development Program of Zhejiang, grant number 2018C03045.

Institutional Review Board Statement: Not applicable.

Informed Consent Statement: Not applicable.

Acknowledgments: The authors gratefully acknowledge the financial supports from the Key Research and Development Program of Zhejiang Province, grant number 2018C03045.

Conflicts of Interest: The authors declare no conflict of interest.

\section{References}

1. Jin, X.; Liao, Z.P. Statistical Research on S-Wave Incident Angle; Disaster Prevention Research Institute Kyoto University: Kyoto, Japan, 1997; Volume 40, pp. 91-97.

2. Tokimatsu, K.; Seed, H.B. Evaluation of settlements in sands due to earthquake shaking. J. Geotech. Eng. 1987, 113, 861-878. [CrossRef]

3. Li, N.; Huang, B.; Ling, D.S. Experimental research on behaviors of saturated loose sand subjected to oblique ellipse stress path. Rock Soil Mech. 2015, 36, 156-170.

4. Huang, J.; Du, X.L.; Tian, Z.M. Effect of the oblique incidence of seismic SV waves on the seismic response of subway station structure. Eng. Mech. 2014, 31, 81-88.

5. Gao, X.J.; Zhao, C.G.; Liu, Q. Seismic response analysis of multi-span viaduct considering topographic effect and soil-structure dynamic interaction based on inclined wave. Eng. Mech. 2011, 28, 237-243

6. Ge, L.Y. Introduction to the New Edition of China's Seismic Wave Parameter Zoning Map and Its Impact on Zhejiang Province. Zhejiang Archit. 2017, 34, 26-28.

7. Panzera, F.; Lombardo, G.; Monaco, C.; Di Stefano, A. Seismic site effects observed on sediments and basaltic lavas outcropping in a test site of Catania, Italy. Nat. Hazard. 2015, 79, 1-27. [CrossRef]

8. Celik, O.C.; Ellingwood, B.R. Seismic fragilities for non-ductile reinforced concrete frames-Role of aleatoric and epistemic uncertainties. Struct. Saf. 2010, 32, 1-12. [CrossRef]

9. Park, J.; Kim, J. Fragility analysis of steel moment frames with various seismic connections subjected to sudden loss of a column. Eng. Struct. 2010, 32, 1547-1555. [CrossRef]

10. Grassl, P.; Xenos, D.; Nyström, U.; Rempling, R.; Gylltoft, K. CDPM2: A damage-plasticity approach to modelling the failure of concrete. Int. J. Solids Struct. 2013, 50, 3805-3816. [CrossRef]

11. Gao, X.; Zhang, Y.; Li, J. Numerical Simulation of a RC Frame Based on ABAQUS Beam Elements. Struct. Eng. 2013, 29, $19-26$.

12. Dassault Systemes Simulia Corp. ABAQUS, Version 6.14; Dassault Systemes Simulia Corp.: Providence, RI, USA, 2014.

13. Zhuang, H.Y.; Yu, X. Dynamic Interaction of Soil-Pile-Isolated Structure; China Building Industry Press: Beijing, China, 2016; pp. 100-108

14. Rayhani, M.H.T.; El Naggar, M.H. Centrifuge modeling of seismic response of layered soft clay. Bull. Earthq. Eng. 2007, 5, 571-589. [CrossRef]

15. Cai, W.Z.; Zhou, J.L.; Zhang, Y.F.; Zhao, Y.J. Evaluation on Features of Soft Foundation Engineering and Bearing Layer of Pile in Jiaxing City. J. Xinjiang Agri. Univ. 2011, 34, 353-357.

16. Belytschko, T.; Liu, W.K.; Moran, B.; Elkhodary, K. Nonlinear Finite Elements for Continua and Structures, 2nd ed.; John Wiley \& Sons: West Sussex, UK, 2014; pp. 399-401.

17. Hudson, M.; Idriss, I. M.; Beikae, M. QUAD4M: A computer program to evaluate the seismic response of soil structures using finite element procedures and incorporating a compliant base. In Structural Engineer; Center for Geotechnical Modeling, Department of Civil and Environmental Engineering, University of California: Davis, CA, USA, 1994. 
18. Nejati, H.R.; Ahmadi, M.; Hashemolhosseini, H. Numerical analysis of ground surface vibration induced by underground train movement. Tunn. Undergr. Space Technol. 2012, 29, 1-9. [CrossRef]

19. Katsanos, E.I.; Sextos, A.G.; Manolis, G.D. Selection of earthquake ground motion records: A state-of-the-art review from a structural engineering perspective. Soil Dyn. Earthq. Eng. 2010, 30, 157-169. [CrossRef]

20. PEER Ground Motion Database. Available online: https://ngawest2.berkeley.edu/ (accessed on 21 December 2020).

21. Hu, X.; Zhou, Z.; Chen, H.; Ren, Y. Seismic Fragility Analysis of Tunnels with Different Buried Depths in a Soft Soil. Sustainability 2020, 12, 892. [CrossRef]

22. Lysmer, J.; Kuhlemeyer, R.L. Finite dynamic model for infinite media. J. Eng. Mech. Div. 1969, 95, 859-878.

23. Liu, J.B.; Gu, Y.; Du, Y.X. Uniform Viscoelastic Artificial Boundary and Viscoelastic Boundary Element. J. Geotech. Eng. 2006, 28, 1070-1075.

24. Zhao, C.; Valliappan, S. A dynamic infinite element for three-dimensional infinite-domain wave problems. Int. J. Numer. Methods Eng. 1993, 36, 2567-2580. [CrossRef]

25. Yang, D.; Wang, Z.L. Numerical analysis of seismic response based on infinite element and wave field separation method. $J$. Tongji Univ. Nat. Sci. 2012, 40, 1129-1134.

26. Huang, B.; Ling, D.S.; Ding, H. Seismic stress path induced by obliquely incident waves and its simulation. Chin. J. Geotech. Eng. 2013, 35, 276-283.

27. Boore, D.M. The effect of simple topography on seismic waves: Implications for the accelerations recorded at Pacoima Dam, San Fernando Valley, California. Bull. Seismol. Soc. 1973, 63, 1603-1609.

28. Choi, Y.; Stewart, J.P.; Graves, R.W. Empirical model for basin effects accounts for basin depth and source location. Bull. Seismol. Soc. Am. 2005, 95, 1412-1427. [CrossRef]

29. Sun, B.T.; Zhang, G.X. Statistical analysis of the seismic vulnerability of various types of structures in Wenchuan M8. 0 earthquake. China Civ. Eng. J. 2012, 45, 26-30.

30. National Standard of the People's Republic of China. Code for Seismic Design of Buildings (GB50011-2010); Ministry of Housing and Urban-Rural Construction of P.R.C.: Beijing, China, 2010.

31. Li, G. Performance-Based Seismic Design of Structures; Science Press: Beijing, China, 2004; pp. 76-85.

32. Cen, W.J.; Du, X.H.; Li, D.J.; Yuan, L.N. Oblique incidence of seismic wave reflecting two components of design ground motion. Shock Vib. 2018, 2018, 4127031. [CrossRef]

33. Lyu, D.; Ma, S.; Yu, C.; Liu, C.; Wang, X.; Yang, B.; Xiao, M. Effects of Oblique Incidence of SV Waves on Nonlinear Seismic Response of a Lined Arched Tunnel. Shock Vib. 2020, 2020, 8093804. [CrossRef]

34. Wang, X.; Chen, J.; Xiao, M. Seismic responses of an underground powerhouse structure subjected to oblique incidence SV and P waves. Soil Dyn. Earthq. Eng. 2019, 119, 130-143. [CrossRef]

35. Li, Q.Q. Theoretical and Numerical Study of Dynamic Stress Paths Caused by Oblique Incident Seismic Waves. Master's Thesis, Zhejiang University, Hangzhou, China, 2017. 